\title{
Tall cell variant of papillary thyroid carcinoma: current evidence on clinicopathologic features and molecular biology
}

\author{
Xiaofei Wang ${ }^{1, *}$, Wenli Cheng ${ }^{2, *}$, Chongqing Liu ${ }^{1}$ and Jingdong $\mathbf{L i}^{1}$ \\ ${ }^{1}$ Department of General Surgery, Affiliated Hospital of North Sichuan Medical College, Nanchong, China \\ 2 Department of Otolaryngology-Head and Neck Surgery, Affiliated Hospital of North Sichuan Medical College, Nanchong, \\ China \\ * These authors have contributed equally to this work \\ Correspondence to: Jingdong Li, email: jingdli@126.com \\ Keywords: thyroid cancer; papillary carcinoma; tall cell; molecular biology; review \\ Received: November 23, $2015 \quad$ Accepted: March 01, $2016 \quad$ Published: March 20, 2016
}

\section{ABSTRACT}

Tall cell variant (TCV) of papillary thyroid carcinoma (PTC) has been recognized for the past few decades as an entity showing aggressive biological behavior; however, there is considerable controversy regarding the definition, clinical and pathological features of TCV because of its rarity and difficult diagnosis. No clinical features can accurately diagnose TCV. Thus, the results of histocytology, immunohistochemistry and molecular genetics tests have important clinical implications for diagnosis. Given the aggressiveness and the increased recurrence and poor survival rates, more aggressive treatment approach and rigorous follow-up is required for patients with TCV. In the present article, we undertook a comprehensive review to summarize and discuss the various aspects of this variant, from morphology to immunohistochemistry, and molecular abnormalities from a practical and daily practice-oriented point of view.

\section{INTRODUCTION}

Although most of papillary thyroid carcinoma (PTC) are indolent with excellent long-term survival, several histological variants of PTC have been found to be associated with more aggressive biologic behavior and poorer prognosis $[1,2]$. Tall cell variant $(\mathrm{TCV})$, the most common aggressive variant of PTC, frequently has vascular invasion, extrathyroidal extension, lymph node metastasis, and distant metastases [3-9], and its 10-year overall and disease-free survival has been reported to be approximately $10 \%$ lower than that of classic PTC (cPTC) [7]. Considering the aggressive clinical features and high mortality, a number of studies on the characteristics and prognosis of TCV have been reported over the last two decades. However, most of the information about this subtype was based on small single institution retrospective studies due to its rarity and difficult diagnosis. Along with increased reported cases of TCV, there is considerable debate regarding the clinical and pathological features of TCV. In order to clarify these issues, we undertook a review to summarize and discuss the clinical, pathological and molecular features of this variant.

\section{DEFINITION}

TCV was first described and defined as a papillary thyroid cancer composed of at least $30 \%$ tall cells by Hawk and Hazard in 1976 [10]. The tall cell is characterized by a height greater than twice its width, eosinophilic cytoplasm, basilar oriented nuclei, besides the classic nuclear features of PTC [11-13]. The 2004 World Health Organization (WHO) classification defined a PTC as TCV if it contained $50 \%$ or more tall cells [14]. However, there is controversy with regard to the proportion of tall cell required for diagnosis of TCV in literature. The threshold of this proportion varies from $10 \%$ to $75 \%$ across these studies with $>30 \%$ being the most commonly used threshold ( $n=10$ studies) $[6,7,13$, $15-21]$, followed by $>50 \%$ ( $n=7$ studies) [3, $8,22-26]$.

The percentage of tall cell necessary to diagnose this variant is various. In one study, Ganly et al [4] found that PTC cases containing 30\%-49\% tall cells and cases containing $\geq 50 \%$ tall cells have similar clinicopathologic features and survival, but both of them bear more aggressive features and poorer prognosis than PTC cases with $<30 \%$ tall cells. Therefore, they recommended the threshold of tall cells in the tumor for the diagnosis of TCV should be set at $30 \%$. However, two other studies 
Table 1: Pooled data of clinical and pathological features in tall cell and cPTC case series

\begin{tabular}{|l|l|l|l|l|l|l|}
\hline \multirow{2}{*}{} & \multicolumn{2}{l}{ Tall cell } & \multicolumn{2}{l|}{ cPTC } \\
\cline { 2 - 7 } & Mean & Range & N & Mean & Range & N \\
\hline Mean age at diagnosis (y) & 50.1 & $41--66$ & 874 & 45.7 & $34--53$ & 2962 \\
\hline Gender (F/M) & 2.9 & $1.0--6.3$ & 843 & 4.1 & $1.4--15$ & 3748 \\
\hline Mean tumor size (mm) & 20.1 & $7--42$ & 505 & 19.0 & $7--28$ & 2760 \\
\hline Mutifocality (\%) & 45.7 & $27.0-61.5$ & 449 & 32.7 & $24.1--45$ & 2300 \\
\hline Extrathyroidal extension (\%) & 63.9 & $33.3-94.1$ & 631 & 33.5 & $0-63.6$ & 2887 \\
\hline Lymph node metastasis (\%) & 59.3 & $23.3-83.3$ & 740 & 33.7 & $12.5-54.8$ & 3467 \\
\hline Distant metastases (\%) & 8.6 & $0-18.2$ & 315 & 3.0 & $0-7.1$ & 1947 \\
\hline Recurrence (\%) & 22.2 & $0-66.7$ & 442 & 6.5 & $0-14.3$ & 1467 \\
\hline Cause-specific death (\%) & 8.3 & $1.5-42.9$ & 290 & 0.03 & $0-0.10$ & 3229 \\
\hline
\end{tabular}

$[27,28]$ found that PTC with $\geq 10 \%$ tall cells demonstrated more aggressive clinicopathologic features than $\mathrm{CPTC}$, and they suggested the presence of more than $10 \%$ tall cells in a tumor should be reported on final pathology reports. Considering the controversial definition on TCV at present, it is rational that the presence of foci of tall cells should be mentioned in pathologic reports irrespective of percentage of tall cell cytology found as suggested by LiVolsi VA [29]. Further studies need to be done to determine the appropriate definition.

\section{EPIDEMIOLOGY}

The incidence of TCV varies from $1.3 \%$ to $13 \%$ of all PTC in literature [3, 18, 21, 24]. The variation in reported prevalence was mainly due to the various diagnostic criteria, difficulty in distinguishing TCV from other variants, and less attention paid to this entity at routine pathological examination. In addition, the incidence of this variant is believed to be underdiagnosed. Several studies $[7,8,16,30]$ have shown that $1-13 \%$ of cases diagnosed as cPTC previously were reclassified as TCV when reviewed by endocrine pathologists. After pooling the information from the literature, the weighted incidence of TCV is $6 \%(95 \% \mathrm{CI}: 4 \%-7 \%)$ (Figure 1$)$.

The incidence of TCV is found to be on the rise with the increasing incidence of PTC worldwide. In one study [31] including $573 \mathrm{TCV}$ and 42,904 cPTC from the Surveillance, Epidemiology, and End Results (SEER) database (1988-2008), authors found the TCV incidence increased by $158 \%$, while the cPTC incidence increased by $60.8 \%$. A similar result was observed in other study [32], which also indicates that TCV incidence has an increase in more recent years. Undoubtedly, a major component of the increased TCV incidence is due to widespread detection of thyroid cancers and more attention on TCV by pathologists. However, similar to the incidence of PTC, whether it is a true increased in TCV is still in controversy, and the reason for this is unknown.

\section{CLINICAL FEATURES}

Similar to cPTC, most studies found that females are predominately affected by TCV. The pooled clinical characteristics of all reported TCV cases and related control patients with cPTC in literature are summarized in Table 1. Of the $843 \mathrm{TCV}$ patients, women accounted for $74 \%(n=625)$, and men accounted for $26 \%(n=$ 218). The female to male ratio was about 2.9 to 1 . In the control patients with cPTC, women accounted for $80 \%$, and men accounted for $20 \%$. The female to male ratio was about 4.1 to 1 . Moreover, some studies observed a male predominance in patients with TCV $[30,33]$. Thus, TCV has a relatively higher prevalence in males than cPTC.

The mean age at presentation of patients with TCV ranges from 41 to 66 years, but the age of cPTC patients ranges from 34 to 53 years in literature. A recent SEER database study [31] also showed that the age at presentation of patient with TCV was older than that of cPTC patients (55.3 years vs. 47.1 years). In addition, another study [34] on SEER database came to similar conclusions. Pooling the data from the reported series so far, the mean age at presentation in patients with TCV and cPTC was 50.1 and 45.7 years respectively (Table 1). Thus, TCV patients tend to be older than those with cPTC at the time of diagnosis.

There is no consensus on whether TCV is different from the cPTC in terms of tumor size, multifocality, lymph node involvement, or distant metastasis at presentation. Pooling of data for this rare variant may answer these questions. As shown in Table 1, the overall rate of multifocality, extrathyroidal extension, lymph node metastasis, and distant metastases at the time of diagnosis in patients with TCV was $45.7 \%, 63.9 \%, 59.3 \%$ and $8.6 \%$ respectively, compared to $32.7 \%, 33.5 \%, 33.7 \%$ and $3.0 \%$ in cPTC patients. The mean tumor diameter in all cases reviewed was $2.0 \mathrm{~cm}$ in $\mathrm{TCV}$ patients and $1.9 \mathrm{~cm}$ in $\mathrm{cPTC}$ patients. Thus, the TCV may be associated with aggressive features when compared to $\mathrm{cPTC}$. 


\section{PRE-OPERATIVE DIAGNOSIS}

Thyroid ultrasound has been widely used to diagnosis of thyroid nodules, and the sonographic features for PTC has been well established, including nodule hypoechogenicity, presence of microcalcifications, irregular margins, and a sharp taller than wide measured on a transverse view $[2,35]$. Due to the rarity of TCV, only one study [23] reported the distinctive sonographic appearance of this variant to date. In that study, Choi et al reviewed the sonographic features of $10 \mathrm{TCV}$ and found that TCV always associated with microlobulated, markedly hypoechoic solid nodules, extrathyroidal extension and lymph node metastasis. Ultrasound elastography for thyroid nodules is gaining more attention recently [36, 37], but its diagnostic value in TCV is still unknown. Thus, further studies focused on the sonographic features of $\mathrm{TCV}$ are required.

Fine needle aspiration biopsy (FNAB) is a readily available and reliable way to diagnose PTC before surgery. In most cases, TCV tumors exhibited many similar cytologic features to those of cPTC, such as the nuclear grooves and nuclear pseudoinclusions. However, given the aggressiveness of this variant tumor, it would be helpful if this variant is distinguished from cPTC by cytologic characteristics on FNAB prior to surgical treatment. According to the evidence in literature [12, 13, 24, 38], the reliable distinguishing features of TCV from $\mathrm{cPTC}$ were large polygonal cells with abundant granular oncocytic cytoplasm, distinct cytoplasmic borders, prominent central nucleoli, and increased numbers of nuclear pseudoinclusions, imparting a "soap bubble" appearance to the nucleus.

\section{CLINICAL MANAGEMENT}

As commented above, TCV tends to occur more frequently in males and older population, with an increased incidence of multifocality, extrathyroidal invasion, lymph node involvement, and distant metastasis at presentation. All of the features associated with worse

\section{Study}

ID 
prognosis point out that patients with TCV should undergo a more aggressive treatment regimen and followed closely. Patients with TCV should be benefit from total thyroidectomy with routine prophylactic central lymph node dissection at initial operation. A therapeutic lateral lymph node dissection should be performed if the lateral lymph nodes involvement is confirmed by preoperative imaging or FNAB. Moreover, because of the high incidence of local nodal involvement and distant metastasis, adjuvant radioactive iodine therapy should be considered for all patients regardless of tumor size. In addition, a more aggressive postoperative thyrotropin suppression therapy and rigorous follow-up should be considered.

\section{PROGNOSIS}

There is a controversy about whether TCV is associated with worse prognosis. It is difficult to perform a well-conducted survival analysis study in a relatively rare disease with a low death rate. Most studies [5, 26, 28,39 ] demonstrated TCV as a more aggressive variant of PTC with higher recurrence and poorer survival compared with cPTC. Similarly, a meta-analysis performed with 131 cases concluded that TCV was a negative prognostic indicator in PTC [40]. However, it has been debated that whether the worse prognosis associated with TCV is attributable to various adverse clinico-pathological parameters or histological type alone. Some studies $[7,18,41]$ have shown that TCV histology was not an independent risk factor for thyroid cancer recurrence and death postoperatively, and the most relevant factors being age, tumor size, extrathyroidal extension, and TNM stage in multivariate analysis.

In contrast, a number of other studies [8, 16, 42] have reported the contrary. They found the histology did independently affect the recurrence and survival on multivariate analysis. Similar results were also reported in one study including $278 \mathrm{TCV}$ patients and $2522 \mathrm{cPTC}$ patients from SEER database. In that study [34], authors found the 5 year disease-specific survival of TCV patients was poorer than all PTC patients $(81.9 \%$ vs. $97.8 \%, P$ $<0.01)$, and it remained poorer $(81.9 \%$ vs. $91.3 \%, P=$ 0.049) when compared with matched cPTC patients for age, sex, presence of gross extrathyroidal disease, regional and distant metastatic stage, and so on. Another study [31] based on the SEER database also found that TCV histology was associated with significantly shorter 5-year overall survival $(80.6 \%$ TCV vs. $93.5 \%$ cPTC, $P<$ 0.01 ) after adjustment. It is interesting that a retrospective analysis of $97 \mathrm{TCV}$ and $18260 \mathrm{cPTC}$ from the SEER database (1998-2009), which limited their analysis only to patients with tumor $\leq 1 \mathrm{~cm}$, did not find a significant differences in overall and disease-specific survival between the histologies [43].

By analyzing the pooled data from the literature, the rates of recurrence and cause-specific death were, respectively, $22.2 \%(98 / 442)$ and $8.3 \%(24 / 290)$ in patients with TCV versus $6.5 \%(96 / 1467)$ and $0.03 \%(84 / 3229)$ in patients with cPTC. Patients with TCV experience higher risk of recurrence and death compared to patients with cPTC.

\section{BIO-MARKERS}

In recent years, the BRAF mutation has emerged as a molecular maker related to aggressive tumor behavior, such as tumor size, extrathyroidal extension, multifocality, lymph nodal metastasis, tumor recurrence and advanced stage in PTC [44-47]. Current evidence suggests that the BRAF mutation has a higher prevalence in TCV with reports ranging from $80 \%$ to $100 \%$ when compared to cPTC with same reports ranging from $63 \%$ to $83 \%[5,26$, $28,39,48]$. Thus, the higher prevalence of BRAF mutation may play a role in the aggressive biological behavior of the TCV. However, additional data are needed for understanding the molecular basis of this aggressiveness.

Rearranged during transfection/papillary thyroid carcinoma (RET/PTC) gene rearrangements are one of the most frequent genetic alterations found in PTC, which were a particular feature of approximately $20 \%$ of PTC [49-51]. Up to now, 13 different RET/PTC oncogenes have been discovered, and RET/PTC1 and RET/PTC3 represent the most common types, accounting for approximately $90 \%$ of RET-associated PTC [51, 52]. Only one study compared the occurrence of RET/PTC between TCV and cPTC in literature. In that investigation [19], a striking correlation between the RET/PTC3 rearrangement and the TCV phenotype was found. Only the RET/PTC3 rearrangement was noted in $35.8 \%(14 / 39)$ of the TCV samples, while the RET/PTC3 rearrangement was noted in $17.2 \%(6 / 39)$ and RET/PTC1 in $10.3 \%(5 / 39)$ of the cPTC samples. The higher incidence of RET/PTC3 in TCV compared to the cPTC suggests that molecular pathogenesis in TCV may be different, which need further studies.

Several immunohistochemical markers have been reported, which may explain the aggressive behavior of TCV. c-Met, a tyrosine kinase receptor, has been implicated in inducing tumor cell motility, survival, proliferation, morphogenesis and angiogenesis [53-55]. It has been demonstrated that c-Met overexpression enhanced the motility and invasiveness of PTC cells [56-58]. Subsequently, c-Met was found to have higher expression in TCV specimens than in CPTC specimens [59]. Similar, MUC1 protein, mediating cell-cell adhesion, and Type IV collagenase, promoting tumor invasion and metastasis, were also shown overexpression in TCV compared with PTC $[60,61]$. Tumor-suppressor p53 plays a critical role in tumor prevention, whose mutation was found in approximately $50 \%$ of all human cancers $[62,63]$. In PTC, overexpression of P53 protein was also observed 
and related to clinicopathologic and prognostic indicators of PTC $[64,65]$. Compared to cPTC, there was a higher rate of $\mathrm{P} 53$ protein overexpression in the TCV samples and the p53 mutant positivity correlated with increased rate of local and distant recurrence [17]. Together, those results provided a rational basis for to distinguish the aggressive subtype from cPTC at a molecular level.

Although recent studies have provided significant insights into the molecular events underlying cPTC, there is no sufficient research on the mechanism of aggressiveness of TCV. Moreover, in order to provide valuable diagnostic, prognostic, and therapeutic information, further study needs to be done for more precise and specific biomarkers.

\section{CONCLUSIONS}

$\mathrm{TCV}$, the most common of the aggressive variant of PTC, has a $6 \%(95 \% \mathrm{CI}: 4 \%-7 \%)$ prevalence in all PTC after pooling the data from the literature, and the prevalence has a significant increasing tendency in more recent years. Although some controversy exists, a number of reports here reviewed, including large database studies, suggest that TCV is more aggressive than CPTC, being associated with older age, bigger tumor diameter, and an increased incidence of multifocality, extrathyroidal extension, lymph node involvement, and distant metastases at presentation, more recurrence and cause-specific death. Thus, more aggressive treatment and rigorous follow-up should be considered for patients with TCV. On the other hand, a number of genetic tests or protein expressions for TCV have been investigated; however, the precise and specific biomarkers for TCV diagnosis or prognosis have not been yet identified, which need more studies.

\section{MATERIALS AND METHODS}

All English language literatures that reported features of TCV and published in peer-review journals were identified by searching PubMed and EMbase databases. Studies with five or more TCV cases were included in this analysis. When the same or overlapping cases were reported in multiple publications, the most updated or complete report with the largest sample size was selected. Following this, the demographic and clinical data of those cases was extracted from each literature source using a pretested form and analyzed using the statistical software SPSS version 16.0 (IBM, New York, USA) and Stata 11.0. A total of 24 individual studies [3-8, 13, 15-28, 39, 59, 66] including 874 patients with TCV met the criteria for critical analysis of the clinical data. To avoid duplicate record, three studies [31, 34, 43] based on SEER database were excluded from data analysis, but they were included in related discussion.

\section{CONFLICTS OF INTEREST}

There is no conflict of interest.

\section{FUNDING}

None.

\section{REFERENCES}

1. Lloyd RV, Buehler D and Khanafshar E. Papillary thyroid carcinoma variants. Head and neck pathology. 2011; 5:5156.

2. American Thyroid Association Guidelines Taskforce on Thyroid N, Differentiated Thyroid C, Cooper DS, Doherty GM, Haugen BR, Kloos RT, Lee SL, Mandel SJ, Mazzaferri EL, McIver B, Pacini F, Schlumberger M, Sherman SI, Steward DL and Tuttle RM. Revised American Thyroid Association management guidelines for patients with thyroid nodules and differentiated thyroid cancer. Thyroid. 2009; 19:1167-1214.

3. Axelsson TA, Hrafnkelsson J, Olafsdottir EJ and Jonasson JG. Tall cell variant of papillary thyroid carcinoma: a population-based study in Iceland. Thyroid. 2015; 25:216220 .

4. Ganly I, Ibrahimpasic T, Rivera M, Nixon I, Palmer F, Patel SG, Tuttle RM, Shah JP and Ghossein R. Prognostic implications of papillary thyroid carcinoma with tall-cell features. Thyroid. 2014; 24:662-670.

5. Erler P, Keutgen XM, Crowley MJ, Zetoune T, Kundel A, Kleiman D, Beninato T, Scognamiglio T, Elemento $\mathrm{O}$, Zarnegar R and Fahey TJ, 3rd. Dicer expression and microRNA dysregulation associate with aggressive features in thyroid cancer. Surgery. 2014; 156:1342-1350; discussion 1350.

6. Bernstein J, Virk RK, Hui P, Prasad A, Westra WH, Tallini G, Adeniran AJ, Udelsman R, Sasaki CT, Roman SA, Sosa JA and Prasad ML. Tall cell variant of papillary thyroid microcarcinoma: clinicopathologic features with BRAF(V600E) mutational analysis. Thyroid. 2013; 23:1525-1531.

7. Michels JJ, Jacques M, Henry-Amar M and Bardet S. Prevalence and prognostic significance of tall cell variant of papillary thyroid carcinoma. Human pathology. 2007; 38:212-219.

8. Ghossein RA, Leboeuf R, Patel KN, Rivera M, Katabi N, Carlson DL, Tallini G, Shaha A, Singh B and Tuttle RM. Tall cell variant of papillary thyroid carcinoma without extrathyroid extension: biologic behavior and clinical implications. Thyroid. 2007; 17:655-661.

9. Robbins and Cotran Pathologic Basis of Disease. Ninth edition (2015) Chapter 24, p 1097.

10. Hawk WA and Hazard JB. The many appearances of papillary carcinoma of the thyroid. Cleveland Clinic 
quarterly. 1976; 43:207-215.

11. Ghossein R and Livolsi VA. Papillary thyroid carcinoma tall cell variant. Thyroid. 2008; 18:1179-1181.

12. Bocklage T, DiTomasso JP, Ramzy I and Ostrowski ML. Tall cell variant of papillary thyroid carcinoma: cytologic features and differential diagnostic considerations. Diagnostic cytopathology. 1997; 17:25-29.

13. Solomon A, Gupta PK, LiVolsi VA and Baloch ZW. Distinguishing tall cell variant of papillary thyroid carcinoma from usual variant of papillary thyroid carcinoma in cytologic specimens. Diagnostic cytopathology. 2002; 27:143-148.

14. DeLellis RA LR, Heitz PU, Eng C (eds). World Health Organization Classification of Tumours: Pathology and Genetics of Tumours of Endocrine Organs. Lyon: IARC Press. 2004:57-66.

15. Johnson TL, Lloyd RV, Thompson NW, Beierwaltes WH and Sisson JC. Prognostic implications of the tall cell variant of papillary thyroid carcinoma. The American journal of surgical pathology. 1988; 12:22-27.

16. Terry JH, St John SA, Karkowski FJ, Suarez JR, Yassa NH, Platica CD and Marti JR. Tall cell papillary thyroid cancer: incidence and prognosis. American journal of surgery. 1994; 168:459-461.

17. Ruter A, Dreifus J, Jones M, Nishiyama R and Lennquist S. Overexpression of p53 in tall cell variants of papillary thyroid carcinoma. Surgery. 1996; 120:1046-1050.

18. Prendiville S, Burman KD, Ringel MD, Shmookler BM, Deeb ZE, Wolfe K, Azumi N, Wartofsky L and Sessions RB. Tall cell variant: an aggressive form of papillary thyroid carcinoma. Otolaryngology - head and neck surgery. 2000; 122:352-357.

19. Basolo F, Giannini R, Monaco C, Melillo RM, Carlomagno F, Pancrazi M, Salvatore G, Chiappetta G, Pacini F, Elisei R, Miccoli P, Pinchera A, Fusco A and Santoro M. Potent mitogenicity of the RET/PTC3 oncogene correlates with its prevalence in tall-cell variant of papillary thyroid carcinoma. The American journal of pathology. 2002; 160:247-254.

20. Machens A, Holzhausen HJ, Lautenschlager C and Dralle $\mathrm{H}$. The tall-cell variant of papillary thyroid carcinoma: a multivariate analysis of clinical risk factors. Langenbeck's archives of surgery / Deutsche Gesellschaft fur Chirurgie. 2004; 389:278-282.

21. Leung AK, Chow SM and Law SC. Clinical features and outcome of the tall cell variant of papillary thyroid carcinoma. The Laryngoscope. 2008; 118:32-38.

22. Lam AK, Lo CY and Lam KS. Papillary carcinoma of thyroid: A 30-yr clinicopathological review of the histological variants. Endocrine pathology. 2005; 16:323330 .

23. Choi YJ, Shin JH, Kim JH, Jung SL, Son EJ and Oh YL. Tall cell variant of papillary thyroid carcinoma: sonographic and clinical findings. Journal of ultrasound in medicine. 2011; 30:853-858.

24. Guan H, Vandenbussche CJ, Erozan YS, Rosenthal DL, Tatsas AD, Olson MT, Zheng R, Auger M and Ali SZ. Can the tall cell variant of papillary thyroid carcinoma be distinguished from the conventional type in fine needle aspirates? A cytomorphologic study with assessment of diagnostic accuracy. Acta cytologica. 2013; 57:534-542.

25. Regalbuto C, Malandrino P, Frasca F, Pellegriti G, Le Moli R, Vigneri R and Pezzino V. The tall cell variant of papillary thyroid carcinoma: clinical and pathological features and outcomes. Journal of endocrinological investigation. 2013; 36:249-254.

26. Lee SH, Jung CK, Bae JS, Jung SL, Choi YJ and Kang CS. Liquid-based cytology improves preoperative diagnostic accuracy of the tall cell variant of papillary thyroid carcinoma. Diagnostic cytopathology. 2014; 42:11-17.

27. Beninato $\mathrm{T}$, Scognamiglio $\mathrm{T}$, Kleiman DA, Uccelli A, Vaca D, Fahey TJ, 3rd and Zarnegar R. Ten percent tall cells confer the aggressive features of the tall cell variant of papillary thyroid carcinoma. Surgery. 2013; 154:13311336; discussion 1336.

28. Oh WJ, Lee YS, Cho U, Bae JS, Lee S, Kim MH, Lim DJ, Park GS, Lee YS and Jung CK. Classic papillary thyroid carcinoma with tall cell features and tall cell variant have similar clinicopathologic features. Korean journal of pathology. 2014; 48:201-208.

29. LiVolsi VA. Papillary carcinoma tall cell variant (TCV): a review. Endocrine pathology. 2010; 21:12-15.

30. Ruter A, Nishiyama R and Lennquist $\mathrm{S}$. Tall-cell variant of papillary thyroid cancer: disregarded entity? World journal of surgery. 1997; 21:15-20; discussion 20-11.

31. Kazaure HS, Roman SA and Sosa JA. Aggressive variants of papillary thyroid cancer: incidence, characteristics and predictors of survival among 43,738 patients. Annals of surgical oncology. 2012; 19:1874-1880.

32. Ceresini G, Corcione L, Michiara M, Sgargi P, Teresi G, Gilli A, Usberti E, Silini E and Ceda GP. Thyroid cancer incidence by histological type and related variants in a mildly iodine-deficient area of Northern Italy, 1998 to 2009. Cancer. 2012; 118:5473-5480.

33. Moreno Egea A, Rodriguez Gonzalez JM, Sola Perez J, Soria Cogollos T and Parrilla Paricio P. Prognostic value of the tall cell variety of papillary cancer of the thyroid. European journal of surgical oncology : the journal of the European Society of Surgical Oncology and the British Association of Surgical Oncology. 1993; 19:517-521.

34. Morris LG, Shaha AR, Tuttle RM, Sikora AG and Ganly I. Tall-cell variant of papillary thyroid carcinoma: a matchedpair analysis of survival. Thyroid. 2010; 20:153-158.

35. Remonti LR, Kramer CK, Leitao CB, Pinto LC and Gross JL. Thyroid ultrasound features and risk of carcinoma: a systematic review and meta-analysis of observational studies. Thyroid. 2015; 25:538-550. 
36. Kwak JY and Kim EK. Ultrasound elastography for thyroid nodules: recent advances. Ultrasonography. 2014; 33:75-82.

37. Sebag F, Vaillant-Lombard J, Berbis J, Griset V, Henry JF, Petit P and Oliver C. Shear wave elastography: a new ultrasound imaging mode for the differential diagnosis of benign and malignant thyroid nodules. The Journal of clinical endocrinology and metabolism. 2010; 95:52815288 .

38. Das DK, Mallik MK, Sharma P, Sheikh ZA, Mathew PA, Sheikh M, Mirza K, Madda JP, Francis IM and Junaid TA. Papillary thyroid carcinoma and its variants in fine needle aspiration smears. A cytomorphologic study with special reference to tall cell variant. Acta cytologica. 2004; 48:325336.

39. Min HS, Lee $\mathrm{C}$ and Jung KC. Correlation of immunohistochemical markers and BRAF mutation status with histological variants of papillary thyroid carcinoma in the Korean population. Journal of Korean medical science. 2013; 28:534-541.

40. Jalisi S, Ainsworth T and Lavalley M. Prognostic outcomes of tall cell variant papillary thyroid cancer: a meta-analysis. Journal of thyroid research. 2010; 2010:325602.

41. Akslen LA and LiVolsi VA. Prognostic significance of histologic grading compared with subclassification of papillary thyroid carcinoma. Cancer. 2000; 88:1902-1908.

42. Ito Y, Hirokawa M, Fukushima M, Inoue H, Yabuta T, Uruno T, Kihara M, Higashiyama T, Takamura Y, Miya A, Kobayashi K, Matsuzuka F and Miyauchi A. Prevalence and prognostic significance of poor differentiation and tall cell variant in papillary carcinoma in Japan. World journal of surgery. 2008; 32:1535-1543; discussion 1544-1535.

43. Kuo EJ, Goffredo P, Sosa JA and Roman SA. Aggressive variants of papillary thyroid microcarcinoma are associated with extrathyroidal spread and lymph-node metastases: a population-level analysis. Thyroid. 2013; 23:1305-1311.

44. Joo JY, Park JY, Yoon YH, Choi B, Kim JM, Jo YS, Shong $\mathrm{M}$ and Koo BS. Prediction of occult central lymph node metastasis in papillary thyroid carcinoma by preoperative BRAF analysis using fine-needle aspiration biopsy: a prospective study. The Journal of clinical endocrinology and metabolism. 2012; 97:3996-4003.

45. Kurtulmus N, Duren M, Ince U, Cengiz Yakicier M, Peker O, Aydin O, Altiok E, Giray S and Azizlerli H. BRAF(V600E) mutation in Turkish patients with papillary thyroid cancer: strong correlation with indicators of tumor aggressiveness. Endocrine. 2012; 42:404-410.

46. Lee X, Gao M, Ji Y, Yu Y, Feng Y, Li Y, Zhang Y, Cheng $\mathrm{W}$ and Zhao W. Analysis of differential BRAF(V600E) mutational status in high aggressive papillary thyroid microcarcinoma. Annals of surgical oncology. 2009; $16: 240-245$

47. Xing M. BRAF mutation in thyroid cancer. Endocrinerelated cancer. 2005; 12:245-262.

48. Basolo F, Torregrossa L, Giannini R, Miccoli M, Lupi C,
Sensi E, Berti P, Elisei R, Vitti P, Baggiani A and Miccoli P. Correlation between the BRAF V600E mutation and tumor invasiveness in papillary thyroid carcinomas smaller than 20 millimeters: analysis of 1060 cases. The Journal of clinical endocrinology and metabolism. 2010; 95:41974205 .

49. Guerra A, Zeppa P, Bifulco M and Vitale M. Concomitant BRAF(V600E) mutation and RET/PTC rearrangement is a frequent occurrence in papillary thyroid carcinoma. Thyroid. 2014; 24:254-259.

50. Romei $\mathrm{C}$ and Elisei R. RET/PTC Translocations and Clinico-Pathological Features in Human Papillary Thyroid Carcinoma. Frontiers in endocrinology. 2012; 3:54.

51. Nikiforov YE. RET/PTC rearrangement in thyroid tumors. Endocrine pathology. 2002; 13:3-16.

52. Prescott JD and Zeiger MA. The RET oncogene in papillary thyroid carcinoma. Cancer. 2015.

53. Cecchi F, Rabe DC and Bottaro DP. Targeting the HGF/Met signalling pathway in cancer. European journal of cancer. 2010; 46:1260-1270.

54. Gherardi E, Birchmeier W, Birchmeier C and Vande Woude G. Targeting MET in cancer: rationale and progress. Nature reviews Cancer. 2012; 12:89-103.

55. Lim YC, Kang HJ and Moon JH. C-Met pathway promotes self-renewal and tumorigenecity of head and neck squamous cell carcinoma stem-like cell. Oral oncology. 2014; 50:633639.

56. Bu R, Uddin S, Ahmed M, Hussain AR, Alsobhi S, Amin T, Al-Nuaim A, Al-Dayel F, Abubaker J, Bavi P and AlKuraya KS. c-Met inhibitor synergizes with tumor necrosis factor-related apoptosis-induced ligand to induce papillary thyroid carcinoma cell death. Molecular medicine. 2012; 18:167-177.

57. Chattopadhyay C, El-Naggar AK, Williams MD and Clayman GL. Small molecule c-MET inhibitor PHA665752: effect on cell growth and motility in papillary thyroid carcinoma. Head \& neck. 2008; 30:991-1000.

58. Koo BS, Kim JM, Seo ST, Yoon YH, Kwon KR, Kim SH, Kwon HW, Bae WJ and Lim YC. Upregulation of HGF and c-MET is associated with subclinical central lymph node metastasis in papillary thyroid microcarcinoma. Annals of surgical oncology. 2014; 21:2310-2317.

59. Nardone HC, Ziober AF, LiVolsi VA, Mandel SJ, Baloch ZW, Weber RS, Mick R and Ziober BL. c-Met expression in tall cell variant papillary carcinoma of the thyroid. Cancer. 2003; 98:1386-1393.

60. Campo E, Merino MJ, Liotta L, Neumann R and StetlerStevenson W. Distribution of the 72-kd type IV collagenase in nonneoplastic and neoplastic thyroid tissue. Human pathology. 1992; 23:1395-1401.

61. Renaud F, Gnemmi V, Devos P, Aubert S, Crepin M, Coppin L, Ramdane N, Bouchindhomme B, d'Herbomez M, Van Seuningen I, Do Cao C, Pattou F, Carnaille B, Pigny P, Wemeau JL and Leteurtre E. MUC1 expression 
in papillary thyroid carcinoma is associated with BRAF mutation and lymph node metastasis; the latter is the most important risk factor of relapse. Thyroid. 2014; 24 :13751384.

62. Morton JP, Timpson P, Karim SA, Ridgway RA, Athineos D, Doyle B, Jamieson NB, Oien KA, Lowy AM, Brunton VG, Frame MC, Evans TR and Sansom OJ. Mutant p53 drives metastasis and overcomes growth arrest/senescence in pancreatic cancer. Proceedings of the National Academy of Sciences of the United States of America. 2010; 107:246251.

63. Muller PA, Caswell PT, Doyle B, Iwanicki MP, Tan EH, Karim S, Lukashchuk N, Gillespie DA, Ludwig RL, Gosselin P, Cromer A, Brugge JS, Sansom OJ, Norman JC and Vousden KH. Mutant p53 drives invasion by promoting integrin recycling. Cell. 2009; 139:1327-1341.
64. Morita N, Ikeda Y and Takami H. Clinical significance of $\mathrm{p} 53$ protein expression in papillary thyroid carcinoma. World journal of surgery. 2008; 32:2617-2622.

65. Shin MK and Kim JW. Clinicopathologic and diagnostic significance of $\mathrm{p} 53$ protein expression in papillary thyroid carcinoma. Asian Pacific journal of cancer prevention : APJCP. 2014; 15:2341-2344.

66. Ostrowski ML and Merino MJ. Tall cell variant of papillary thyroid carcinoma: a reassessment and immunohistochemical study with comparison to the usual type of papillary carcinoma of the thyroid. The American journal of surgical pathology. 1996; 20:964-974. 